\author{
Giorgio Zanchin \\ Filippo Dainese \\ Federico Mainardi \\ Ferdinando Maggioni
}

\section{Clinical experience with triptans}

G. Zanchin $(\varangle) \cdot$ F. Dainese

F. Mainardi $\bullet$ F. Maggioni

Department of Neurosciences, University of

Via Giustiniani 5 ,

I-35128 Padua, Italy

e-mail: giorgio.zanchin@unipd.it

Tel.: 049-8213600/26

Fax: 049-8751770

\begin{abstract}
Many drugs are now available for treating migraine attacks, including agents specifically indicated for this condition. Since 1990 sumatriptan, the first $5-\mathrm{HT}_{1 \mathrm{~B}, 1 \mathrm{D}}$ receptor agonist, was introduced and realized a real breakthrough in therapy; other agents of this class of drugs called triptans have more recently been used. All of them are effective in relieving the symptoms of migraine, but each exhibits pharmacological and/or clinical features that must be considered for the optimal care and management of the patient. We present here a short overview on the main clinical features of the triptans already in use in Italy.
\end{abstract}

Key words Triptans $\cdot$ Migraine $\cdot$ Clinical use - Sumatriptan, Zolmitriptan $\cdot$ Rizatriptan

\section{Introduction}

Migraine is a common episodic headache disorder with a prevalence of approximately $18 \%$ in women, $6 \%$ in men, and $4 \%$ in children, according to the American Migraine Study [1]. For a good management of this disorder, active participation of the patient is requested. The pharmacologic treatment of migraine may be acute or prophylactic, and patients with frequent, severe attacks require both approaches. It is of paramount importance to take a detailed anamnesis and perform an accurate neurological examination in order to: exclude a secondary cause, identify and eliminate possible headache-provoking factors, instruct the patient to distinguish between different headache types, and to start early the treatment of the attack.
Quickly relieving the symptoms with an early intervention at the very beginning of a migraine attack and allowing the patient to return promptly to his usual occupation are the goals of acute therapy [2]. The abortive medication can be specific or non-specific. Non-specific medication (e.g. NSAIDs, antiemetics, combinations) is used to control the pain and associated symptoms of migraine as well as other pain disorders, while specific medications act solely on migraine attacks. Patients with mild to moderate attacks can use non-specific medications. Patients with more severe migraine and those whose headaches are known to respond poorly to simple NSAIDs and combination analgesics should be treated with specific agents (e.g. triptans, ergot derivatives). However ergots, being non-selective serotonin-receptor agonists, can cause a 
number of undesired effects, including the aggravation of nausea and vomiting, and have many contraindications [2].

\section{Triptans}

Triptans are 5-hydroxytriptamine (5-HT) agonists with a selective action mainly on the $\mathrm{HT}_{1 \mathrm{~B}}$ and $\mathrm{HT}_{1 \mathrm{D}}$ receptors, considered to be pivotal in the mechanisms of migraine attack development. Their first representative, sumatriptan, was introduced in migraine treatment almost twelve years ago. Since then, zolmitriptan and rizatriptan have become available in Italy, whereas others triptans such as naratriptan, eletriptan, almotriptan and frovatriptan are being studied or are already in use in other countries. These drugs are prescribed as a first-line treatment for severe-moderate migraine attacks or as an escape medication for less intense attacks when simpler measures are ineffective.

In clinical trials, the efficacy measures include:

- Headache response or percentage of patients whose headache intensity lessens, from moderate or severe at baseline to mild or absent at $2 \mathrm{~h}$;

- Pain-free response, percentage of patients who become pain-free at $2 \mathrm{~h}$;

- Patient function, the improvement in the sufferer's functional abilities;

- Relief of migraine-associated symptoms, nausea, vomiting, photophobia and phonophobia;

- Use and timing of rescue medication; and

- Headache recurrence, i.e. the return of moderate or severe headache within $24 \mathrm{~h}$ after an initial response $2 \mathrm{~h}$ after dosing [3].
A more recent efficacy measure is the sustained painfree response, which includes patients who are pain-free at $2 \mathrm{~h}$, do not have headache recurrence, and do not need rescue medications within $24 \mathrm{~h}$ [3]. Other recently introduced parameters are the therapeutic gain (the difference between the response to active drug and the response to placebo, Table 1) and the number needed to treat (the reciprocal of the therapeutic gain, i.e. the number of patients that have to receive the active treatment for one of them to benefit from that therapy). These measures are used to compare drugs tested in different clinical trials, but variable placebo response rates can distort meta-analytic comparisons of active therapies [4].

In clinical practice, the treatment should be tailored to the individual migraine patient and to the individual attack. The following factors should be taken into account: different doses; forms of administration; previous experience with triptans, with regards not only to their efficacy, but also to adverse events; and possible contraindications. All of these agents appear to be well tolerated, but cardiovascular risk factors should be carefully screened. At therapeutic concentrations, the triptans selectively contract middle meningeal arteries, so that myocardial vasoconstriction is not relevant in patients with healthy coronary arteries. In patients with pre-existing arterial lesions who have only a limited coronary reserve, documented silent ischemia, angina pectoris, or Prinzmetal's angina, the use of triptans is contraindicated. Triptans should also not be used in patients with uncontrolled hypertension, cerebrovascular disease or vertebrobasilar or hemiplegic migraine or in patients who are at risk for these conditions $[5,6]$. Their concomitant use, within 24 hours, with an ergotamine-containing preparation must be avoided, due to possible pharmacological potentiation [6].

Table 1 Triptan efficacy against migraine in controlled clinical trials. Data refer to the response at $2 \mathrm{~h}$ (Modified from [3])

\begin{tabular}{|c|c|c|c|c|c|}
\hline Drug & $\begin{array}{l}\text { Dose }(\mathrm{mg} \\
\text { of admi }\end{array}$ & $\begin{array}{l}\text { and route } \\
\text { stration }\end{array}$ & $\begin{array}{l}\text { Active response } \\
\text { rate, }(\%)\end{array}$ & $\begin{array}{c}\text { Placebo response } \\
\text { rate, }(\%)\end{array}$ & $\begin{array}{c}\text { Therapeutic } \\
\text { gain, } \%\end{array}$ \\
\hline \multirow[t]{6}{*}{ Sumatriptan } & 6 & $\mathrm{sc}$ & $81-82$ & $31-39$ & $43-50$ \\
\hline & 100 & po & $56-62$ & $17-26$ & $30-40$ \\
\hline & 50 & po & $50-61$ & $17-27$ & 24-37 \\
\hline & 25 & po & 52 & $17-27$ & $25-35$ \\
\hline & 20 & in & $55-64$ & $25-36$ & 24-39 \\
\hline & 25 & $\mathrm{pr}$ & 70 & 39 & 31 \\
\hline \multirow[t]{2}{*}{ Zolmitriptan } & 2.5 & po & $62-65$ & $34-36$ & $25-31$ \\
\hline & 50 & po & $59-67$ & $16-44$ & $15-47$ \\
\hline Naratriptan & 2.5 & po & $43-50$ & $18-27$ & $16-28$ \\
\hline \multirow[t]{2}{*}{ Rizatriptan } & 5 & po & $60-63$ & $23-40$ & $20-40$ \\
\hline & 10 & po & $67-77$ & $35-40$ & $27-40$ \\
\hline \multirow[t]{2}{*}{ Rizatriptan MLT } & 5 & po & 66 & 47 & 19 \\
\hline & 10 & po & 74 & 28 & 46 \\
\hline
\end{tabular}

$s c$, subcutaneous; $p o$, per os; in, intranasal; $p r$, suppository 
When prescribing triptans to patients taking selective serotonin reuptake inhibitors, the uncommon occurrence of serotonin syndrome must be considered; this is a rare clinical entity resulting from an increased level of serotonin in the central nervous system secondary to the interactions between serotoninergic agonists. The most frequent features are hyperreflexia, diaphoresis, changes in mental status, myoclonus, fever and tremor. The incidence of serotonin syndrome is not known; however, with the increasing use of migraine medications active on serotonin receptors, the number of cases observed is most likely to increase. The serotonin syndrome occurs within hours to days after adding a serotoninergic agonist, and improves generally within $24 \mathrm{~h}$ after drug withdrawal and supportive therapy. If symptoms persist, the patient can be treated with cyproheptadin, a serotonin receptor blocker [7].

\section{Sumatriptan}

Sumatriptan first became available as a subcutaneous injection formulation (6 mg) in 1990. Presently it is also available as an oral tablet (50 and $100 \mathrm{mg}$ ), nasal spray (20 $\mathrm{mg}$ ) and suppository (25 $\mathrm{mg}$ ). All formulations are rapidly absorbed, although the bioavailability is much higher in the case of subcutaneous administration (96\% vs. 15\%); the $\mathrm{T}_{\max }$ is $0.17 \mathrm{~h}$ for subcutaneous administration and 1.5-2.0 $\mathrm{h}$ for other formulations, whereas the $\mathrm{T}_{1 / 2}$ is about $2 \mathrm{~h}$ regardless of the route. Sumatriptan is metabolized by monoamine oxidase-A (MAO-A) [6-8]. Fourteen placebo-controlled trials have consistently shown that sumatriptan injection is superior to placebo for headache relief at $1 \mathrm{~h}(70 \%-80 \%$ vs. $18 \%-26 \%)$ and at $2 \mathrm{~h}(56 \%-77 \%$ vs. $18 \%-26 \%) ; 12 \%-20 \%$ of patients treated needed rescue medication versus $40 \%-61 \%$ of those treated with placebo [6]. With the use of a 100-mg oral tablet, there is a significantly more effective relief of headache than with placebo $(50 \%-71 \%$ vs. $17 \%-31 \%) 2 \mathrm{~h}$ after dosing $[6,8]$.

The recommended dose is $50 \mathrm{mg}$, although some patients may require $100 \mathrm{mg}$. In a recent patient preference study comparing $50 \mathrm{mg}$ and $100 \mathrm{mg}$, less than onethird of patients needed the 100-mg dose [9]. If headache recurs, further doses may be added any time after $2 \mathrm{~h}$ as long as no more than $300 \mathrm{mg}$ is taken within a 24-h period. The recommended dose for injection is $6 \mathrm{mg}$ and up to two injections are permitted in $24 \mathrm{~h}$, with an interval of at least $1 \mathrm{~h}$ between doses.

For intranasal administration, the dose is $20 \mathrm{mg}$, and up to 2 doses are permitted in $24 \mathrm{~h}$, with a minimum of $2 \mathrm{~h}$ between sprays. Relief occurs as quickly as in 15 min, and within $2 \mathrm{~h} 70 \%$ of patients have pain relief [8]. The mean therapeutic gains at 30 and $120 \mathrm{~min}$ (37\% and
$33 \%$, respectively) are similar to that of oral administration, but after $4 \mathrm{~h}$ the oral route is superior to intranasal administration [10].

Significant headache relief has also been achieved with suppositories. At the recommended dose of $25 \mathrm{mg}$, the mean therapeutic gain is $31 \%$ at $2 \mathrm{~h}$ (Table 1) [6]. In clinical practice, about $75 \%$ of patients are reported to experience headache recurrence at least in some attacks and up to $40 \%$ in most attacks, with a median time of 10 $\mathrm{h}$ for subcutaneous and $12 \mathrm{~h}$ for oral administration [11]. The efficacy of sumatriptan in treating recurrent headache has been investigated in four trials, where the therapeutic gain was 34\% [6]. Both 2 and $4 \mathrm{~h}$ after treatment, nausea, vomiting, photophobia and phonophobia improved in a greater number of patients $(70 \%-80 \%)$ receiving sumatriptan compared with placebo $(35 \%-45 \%)$ [12].

\section{Zolmitriptan}

Zolmitriptan, the second triptan to be marketed, was designed to be more lipophilic than sumatriptan, and therefore to be able to cross the blood-brain barrier. Zolmitriptan is available as a tablet and, more recently, as a rapidly dispersible preparation. It has an oral biovailability of $46 \%$, a $\mathrm{T}_{\max }$ of $1.5 \mathrm{~h}$ and a $\mathrm{T}_{1 / 2}$ of $3 \mathrm{~h}$. Zolmitriptan is metabolized through the $\mathrm{P} 450$ system and its active metabolite is degraded by MAO-A [10]. The optimum dose is $2.5 \mathrm{mg}$ [13]. If symptoms persist a second dose, with a 2-h interval, may be taken. If the first dose does not bring sufficient relief, subsequent attacks can be treated with $5 \mathrm{mg}$, with a maximum of $10 \mathrm{mg}$ in 24 h. Zolmitriptan is contraindicated in patients with severe renal impairment (creatinine clearance $<15 \mathrm{ml} / \mathrm{min}$ ) and no more than $5 \mathrm{mg}$ in a $24 \mathrm{~h}$ period should be taken in patients with severe hepatic impairment [10]. The clinical trials of zolmitriptan $(2.5 \mathrm{mg})$ vs. placebo showed a 2-h headache response of $50 \%-77 \%$ vs. $19 \%-34 \%$, with a therapeutic gain of $29 \%$. A recurrence rate of $22 \%$ after $2.5 \mathrm{mg}$ was reported [13]. Also, zolmitriptan effectively relieved migraine-associated symptoms such as nausea, photophobia and phonophobia, and reduced activity impairment $[6,8,10,13]$.

\section{Rizatriptan}

Rizatriptan, available both as a regular tablet and as a rapidly dispersible tablet, is a lipophilic $5 \mathrm{HT}_{1 \mathrm{~B} / 1 \mathrm{D}}$ agonist with rapid absorption. Rizatriptan has an oral bioavalability of $40 \%$, a $\mathrm{T}_{\max }$ of $1 \mathrm{~h}$ and a $\mathrm{T}_{1 / 2}$ of $2 \mathrm{~h}$; it is large- 
ly metabolized by MAO-A [6]. The recommended dose is $10 \mathrm{mg}$, with a maximum of $20 \mathrm{mg}$ in a 24-h period; or $5 \mathrm{mg}$, with a maximum of $15 \mathrm{mg}$, in patients with hepatic or renal impairment or in those using propranolol [6, 14], whereas nadolol and metoprolol do not increase its plasma concentration [10]. If headache returns after an initial relief, a second dose may be taken not earlier than $2 \mathrm{~h}$ after the first one.

In clinical trials versus placebo, rizatriptan $(10 \mathrm{mg}$ tablet) produced a headache response at $2 \mathrm{~h}$ of $69 \%-77 \%$ vs. $23 \%-40 \%$, with a mean therapeutic gain of $35 \%$ after $2 \mathrm{~h}$; with the wafer, the mean therapeutic gain was $37 \%$ for $10 \mathrm{mg}$ and $28 \%$ for $5 \mathrm{mg}[6,8,14]$. In the treatment of recurrence, the 5-mg dose was not significantly superior to placebo, but $10 \mathrm{mg}$ showed a therapeutic gain of $38 \%$ after $2 \mathrm{~h} \mathrm{[10].} \mathrm{A} \mathrm{greater} \mathrm{reduction} \mathrm{in} \mathrm{the} \mathrm{inci-}$ dence of associated symptoms was observed in patients who took rizatriptan $(10 \mathrm{mg})$ compared with placebo $(60 \%-77 \%$ vs. $41 \%-50 \%)$ [14].

\section{Other triptans}

Other triptans have been extensively investigated or marketed in other countries. However, since they are not yet available for clinical use in Italy, here we will merely summarize some information on them. Naratriptan has a bioavailability of $74 \%$, a $\mathrm{T}_{\max }$ of $2 \mathrm{~h}$ and a $\mathrm{T}_{1 / 2}$ of $5.5 \mathrm{~h}$. At the 2.5-mg dose, it provides meaningful headache relief $4 \mathrm{~h}$ after dosing and has a relatively low rate of recurrence $(16 \%-28 \%)$, but also a minor therapeutic gain $(22 \%-28 \%)$ [6].
Eletriptan has a bioavailability of $50 \%$, a $\mathrm{T}_{\max }$ of 1.4 $\mathrm{h}$ and a $\mathrm{T}_{1 / 2}$ of $6.3 \mathrm{~h}$; in 4 placebo-controlled trials, the mean therapeutic gain was $42 \%$ after $2 \mathrm{~h}$ for the $80-\mathrm{mg}$ tablet and $37 \%$ for the $40-\mathrm{mg}$ tablet [10].

Almotriptan has a bioavailability of $80 \%$, a $\mathrm{T}_{\max }$ of $2.5 \mathrm{~h}$ and $\mathrm{a} \mathrm{T}_{1 / 2}$ of $3.1 \mathrm{~h}$. At an oral dose of $12.5 \mathrm{mg}$, it appears to be a safe antimigraine treatment with a mean therapeutic gain of $26 \%$ after $2 \mathrm{~h}$ [6]. Small clinical trials and no peer-reviewed papers on frovatriptan have been published $[6,8]$.

\section{Safety and tolerability of triptans}

Among the more commmon adverse events associated with triptans are the injection site reaction present in $40 \%$ of patients with subcutaneous sumatriptan, and the taste disturbance (bitter, unpleasant) in $25 \%-36 \%$ of patients receiving nasal spray. However, these are limited to subcutaneous and nasal formulations, respectively [6].

More in general, the adverse events reported in clinical trials and in clinical practice can be resumed in the so-called triptan syndrome, which includes tingling, numbness, warm/hot sensations, heaviness, pressure or tightness in different parts of the body but especially in the chest, asthenia, dizziness and somnolence. These are experienced in 1\%-10\% of patients (Table 2) [14-16]. They are typically mild and short-termed, disappearing within $30 \mathrm{~min}$ in almost all patients, and do not increase with cumulative administrations over a series of attacks [10]. In clinical practice, about $20 \%$ of patients with tablet and $40 \%$ with injection are reported to experience

Table 2 Percent incidence of most common adverse events in some placebo-controlled trials

\begin{tabular}{|c|c|c|c|c|c|c|c|c|c|c|}
\hline \multirow[t]{2}{*}{ Adverse event } & \multicolumn{2}{|c|}{$\begin{array}{l}\text { Sumatriptan }{ }^{\mathrm{a}} \\
6 \mathrm{mg} \mathrm{sc}\end{array}$} & \multicolumn{2}{|c|}{$\begin{array}{l}\text { Sumatriptan } \\
50 \mathrm{mg} \text { po }\end{array}$} & \multicolumn{2}{|c|}{$\begin{array}{l}\text { Sumatriptan } \\
100 \mathrm{mg} \text { po }\end{array}$} & \multicolumn{2}{|c|}{$\begin{array}{l}\text { Zolmitriptan } \\
2.5 \mathrm{mg} \text { po }\end{array}$} & \multicolumn{2}{|c|}{$\begin{array}{l}\text { Rizatriptan } \\
10 \text { mg po }\end{array}$} \\
\hline & Drug & Placebo & Drug & Placebo & Drug & Placebo & Drug & Placebo & Drug & Placebo \\
\hline Injection-site reaction & 59 & 24 & - & - & - & - & - & - & - & - \\
\hline Nausea & - & - & 6 & 2 & 4 & 2 & 9 & 4 & 6 & 3 \\
\hline Asthenia/fatigue & 5 & $<1$ & 3 & 1 & 5 & 1 & 6 & 3 & 8 & 4 \\
\hline Warm sensation & 11 & 4 & 2 & 2 & 3 & 2 & 4 & 2 & - & - \\
\hline Dizziness & 12 & 4 & 1 & 2 & 5 & 2 & 8 & 4 & 8 & 4 \\
\hline Somnolence & - & - & - & - & - & - & 6 & 3 & 9 & 6 \\
\hline Heaviness & 7 & 1 & - & - & - & - & 2 & $<1$ & - & - \\
\hline Flushing & 7 & 2 & - & - & - & - & - & - & 2.2 & 1.2 \\
\hline Dry mouth & - & - & - & - & - & - & 3 & 2 & 3.8 & 1.2 \\
\hline Paresthesia & - & - & 5 & 2 & 3 & 2 & 6 & 1 & - & - \\
\hline Chest tightness, pressure & 7 & 2 & 2 & 1 & 2 & 1 & 3 & $<1$ & 3 & 3 \\
\hline
\end{tabular}

$s c$, subcutaneous; $p o$, per os; -, not considered

${ }^{a}$ From [15]; ${ }^{b}$ From [16]; ${ }^{c}$ From [6]; ${ }^{d}$ From [14] 
triptan symptoms in association with sumatriptan [6]. Chest pain associated with the use of sumatriptan has been observed but, with rare exceptions, it lacks temporal, electrocardiographic, angiographic and enzymatic evidence of myocardial involvement. In more than 9 million patient exposures to sumatriptan in more than 236 million attacks, significant cardiovascular and neurological events were rare. Nevertheless, a careful investigation for the presence of the already mentioned cardiovascular risk factors is always recommended [15].

Clinical experience shows that there is not a predictable relationship between the frequency of adverse events and the pharmacological parameters of triptans. On the basis of the higher lipophilicity of zolmitriptan and rizatriptan, the incidence of adverse events such as dizziness and somnolence was expected to be greater than that observed with sumatriptan, but it does not appear to be so.

\section{General considerations}

In clinical practice, triptans are effective in relieving the symptoms of migraine and are usually well tolerated. Most patients prefer the oral route of administration and in particular the rapid dispersible tablet, that is generally well accepted even in presence of nausea because no liquids are required for its administration. If severe nausea or vomiting is present, the intranasal, rectal or subcutaneous administrations, available at present for sumatriptan only, should be tried. It is advisable to explain to the patient the different formulations available, so that the most convenient one for that specific attack can be chosen.

Quick relief of pain is a high priority for migraine patients. Clinically, subcutaneous sumatriptan has an onset of action of less than $10 \mathrm{~min}$, that for the intranasal route is $15 \mathrm{~min}$, for the tablet $30 \mathrm{~min}$, and for the suppository $30-60 \mathrm{~min}$ [6]. In contrast, rizatriptan $(10 \mathrm{mg}$ ) acts at $30 \mathrm{~min}$ and zolmitriptan $(2.5 \mathrm{mg})$ at $30-45 \mathrm{~min}$. No difference in speed of onset is observed between the regular tablet and the rapidly dispersible tablet.

When recurrence occurs, combinations of a triptan and an NSAID can decrease it significantly. Before considering a patient to be a non-responder, a triptan should be used in at least three attacks. If a patient does not have pain relief, the dose should be increased if well tolerated, or a different form of administration should be used. Since the response to different triptans seems to be unpredictable, another triptan should also be tried. Finally, a trial with subcutaneous sumatriptan can be considered.

Among responders, the availability of different triptans allows the identification of groups of patients with different clinical needs, who therefore may get the optimal result from one instead of from another triptan or formulation, according to their pharmacological features (e.g. speed of action, recurrence) on one side, and to the individual response on the other.

The administration of triptans during aura is discouraged, since it is not useful for the symptoms of aura and seems to lessen the efficacy on the headache phase.

With regard to compliance, it is important to inform the patient about the triptan symptoms and, in particular, the chest symptoms, so he or she can be reassured about their benign nature.

Since there have been no studies on the use of triptans in pregnancy, these drugs are contraindicated in this condition, although recent data on the use of sumatriptan in early pregnancy does not bear evidence of an increase in the teratogenic risk nor in the rate of congenital malformation [17]. It is safe to breastfeed while taking triptans, provided the milk produced within $8 \mathrm{~h}$ of the administration of sumatriptan is not given to the baby [6].

There are no studies on the use of triptans on patients older than 65 years, and therefore their administration above this age is contraindicated.

The use of triptans in children has not yet been well studied. Results from limited clinical trials considering patients over 12 years of age show a tolerability similar to that seen in adults, but a smaller efficacy. With sumatriptan (50 and $100 \mathrm{mg}$ ), $22 \%$ of children became painfree at $2 \mathrm{~h}$ and $30 \%$ obtained some relief at $2 \mathrm{~h}$; the response rate to placebo was high $(25 \%-42 \%)$. The recommended dose is $50 \mathrm{mg}$ for children aged 6-12 years and $100 \mathrm{mg}$ for those over 12 years or in children with a body surface area of $1.5 \mathrm{~m}^{2}$ or more or with a weight over $50 \mathrm{~kg}$ [18]. A better response rate has been found with intranasal formulation: complete relief at $2 \mathrm{~h}$ using $20 \mathrm{mg}$ was significantly greater compared with that from placebo (36\% vs. 25\%) [19]. The limited reports available on zolmitriptan, rizatriptan and oral sumatriptan in children and adolescents seem to indicate that their use is safe. However, at the moment triptans in children should be used only when other therapeutic options have failed.

Finally, to avoid abuse, migraine patients should not be allowed a prolonged daily use of triptans. A limit of about 10 doses per month is suggested. 


\section{References}

1. Lipton RB, Steward WF (1993) Migraine in the United States: a review of epidemiology and health care use. Neurology 43(S3):S6-S10

2. Silberstein SD, Goadsby PJ, Lipton RB (2000) Management of migraine: an algorithmic approach. Neurology 55(S2):S46-S52

3. Sheftell FD, Fox AW (2000) Acute migraine treatment outcome measures: a clinicians's view. Cephalalgia 20(S2):14-24

4. Sheftell FD, Fox AW, Randall EW, Tepper SJ (2001) Differentiating the efficacy of 5-H $\mathrm{H}_{\mathrm{T} 1 \mathrm{~B} / 1 \mathrm{D}}$ agonist. Headache 41:257-263

5. Maassen VanDenBrink A, Van Den Broek RWM, De Vries R, Bogers AJ, Avezzat CJ, Saxena PR (2000) Craniovascular selectivity of eletriptan and sumatriptan in human isolated blood vessels. Neurology 55:1524-1530

6. Saxena PR, Tfelt-Hansen P (2000) Triptans, $5 \mathrm{H}_{\mathrm{T} 1 \mathrm{~B} / 1 \mathrm{D}}$ receptor agonists in the acute treatment of migraine. In: Olesen J, Tfelt-Hanson P, Welch KMA (eds) The headaches. Lippincott Williams \& Wilkins, Philadelphia, pp 411-438

7. Mathew NT, Tietjen GE, Lucker C (1996) Serotonin syndrome complicating migraine pharmacotherapy. Cephalalgia 16:323-327
8. Spiering ELH (2001) Advances in migraine treatment: the triptans. The Neurologist 7:113-121

9. Zanchin G, Roncolato M, Fabbri L (2000) Sumatriptan (50 and $100 \mathrm{mg}$ ) in repeated migraine attacks: a patient preference study. J Headache Pain 1:33-38

10. Tfelt-Hansen P, De Vries P, Saxena PR (2000) Triptans in migraine, a comparative review of pharmacology, pharmacokinetics and efficacy. Drugs 60(6):1259-1287

11. Visser WH, de Vriend RH, Jaspers MW, Ferrari MD (1996) Sumatriptan in clinical practice: a $2-y e a r$ review of 453 migraine patients. Neurology 47:46-51

12. Cutler N, Mushet GR, Davids R, Clements B, Whitcher L (1995) Oral sumatriptan for the acute treatment of migraine: evaluation of three dosage strengths. Neurology 45(S7):S5-S9

13. Solomon GD, Cady RK, Klapper JA, Earl NL, Saper JR, Ramadan N, on behalf of the 042 Clinical Study Group (1997) The clinical efficacy and tolerability of $2.5 \mathrm{mg}$ zolmitrip$\tan$ for the acute treatment of migraine. Neurology 49:1219-1225

14. Kramer MS, Matzura-Wolfe D, Polis A, Getson A, Amarameni PG, Solbach MP, McHugh W, Feighner J, Silberstein S, Reines SA and the Rizatriptan Multiple Attack Study Group (1998) A placebo-controlled crossover study of rizatriptan in the treatment of multiple migraine attacks. Neurology 51:773-781
15. Welch KMA, Mathew NT, Stone P, Rosamond W, Saiers J, Gutterman D (2000) Tolerability of sumatripan: clinical trials and post-marketing experience. Cephalalgia 20:687-695

16. Pfaffenrath V, Cunin G, Sjonell G, Prendergast S (1998) Efficacy and safety of sumatriptan tablets in the acute treatment of migraine: defining the optimum dose of oral sumatriptan. Headache 38:184-190

17. Kallen B, Lygner PE (2001) Delivery outcome in women who used drugs for migraine during pregnancy with special reference to sumatriptan. Headache 41:351-356

18. Hamalainen ML, Hoppu K, Santavuori P (1997) Sumatriptan for migraine attacks in children: a randomized placebo-controlled study. Neuology 48:1100-1103

19. Winner P, Rothner AD, Saper J, Nett $\mathrm{R}$, Asgharnejad M, Laurenza A, Austin R, Peykamian M (2000) A randomizzed, double-blind, placebocontrolled study of sumatriptan nasal spray in the treatment of acute migraine in adolescent. Pediatrics 106:989-997 